\title{
ANAC044 modulates P reutilization in P deficient Arabidopsis thaliana root cell wall in an ethylene dependent manner
}

\author{
Qi Wu ${ }^{1}$, ye Tao ${ }^{1}$, xiaolong Zhang ${ }^{1}$, Xiao Fang Zhu ${ }^{1}$, and Ren Fang Shen ${ }^{1}$ \\ ${ }^{1}$ State Key Laboratory of Soil and Sustainable Agriculture, Institute of Soil Science, \\ Chinese Academy of Sciences
}

July 7,2020

\begin{abstract}
Phosphorus (P) deficiency is a major problem in agriculture, thus identifying factors affecting plant's ability to reutilize previously assimilated $\mathrm{P}$ is a prerequisite for improving the $\mathrm{P}$ homeostasis in crops grown with $\mathrm{P}$ deficient soil. Here, we report the involvement of a NAC (No apical meristem [NAM], Arabidopsis transcription activation factor [ATAF] and Cup-shaped cotyledon $[\mathrm{CUC}]$ ) transcription factor in P deficiency resistance in Arabidopsis. Compared to the wild type (WT, Col-0) plants, the anac044 mutant displayed $\mathrm{P}$ deficiency resistant phenotype, together with the increasing root length, root and shoot biomass under P deficiency. ANAC044 was frequently expressed, including roots and shoots. Upon P deficient treatment even within $1 \mathrm{~d}$, ANAC044 transcript accumulation was strongly up-regulated. Further analysis revealed that, under P-deficient condition, the cell wall, particularly the pectin of anac044, released more $\mathrm{P}$ than that of WT, accompanied by an increment of ethylene production, as a result, more soluble $\mathrm{P}$ was available in anac044 root and shoot. Thus, the study here uncovers the role of ANAC044 in maintenance of P homeostasis through ethylene signaling.
\end{abstract}

\section{Hosted file}

main document.docx available at https://authorea.com/users/340580/articles/467758-anac044modulates-p-reutilization-in-p-deficient-arabidopsis-thaliana-root-cell-wall-in-anethylene-dependent-manner

\section{Hosted file}

figures.docx available at https://authorea.com/users/340580/articles/467758-anac044modulates-p-reutilization-in-p-deficient-arabidopsis-thaliana-root-cell-wall-in-anethylene-dependent-manner 